\title{
Direct Demonstration of a Physiological Role for Carbon Monoxide in Olfactory Receptor Neurons
}

\author{
Tatsuya Ingi ${ }^{1}$ and Gabriele V. Ronnett ${ }^{1,2}$ \\ Departments of ${ }^{1}$ Neuroscience and ${ }^{2}$ Neurology, The Johns Hopkins University School of Medicine, Baltimore, \\ Maryland 21205
}

Recent evidence suggests that, like nitric oxide (NO), carbon monoxide (CO), another activator of soluble guanylyl cyclase, may serve as an intercellular messenger in the brain. Heme oxygenase, which converts heme to biliverdin and $\mathrm{CO}$, is abundantly expressed in the brain and is localized to discrete neuronal populations. However, evidence for the actual generation of $\mathrm{CO}$ by neurons is lacking. Heme oxygenase-2 immunoreactivity is abundantly present in olfactory receptor neurons where it essentially colocalizes with immunoreactivity to soluble guanylyl cyclase, the target of $\mathrm{CO}$ action. To examine the generation of $\mathrm{CO}$ by neurons, we measured $\mathrm{CO}$ production directly and determined its relationship to cyclic GMP levels in cultured rat olfactory receptor neurons. This system has the advantage of not having measurable NO production, which could confound results since NO is a more potent activator of guanylyl cyclase than $\mathrm{CO}$. Metabolic labeling experiments permitted the direct measurement of ${ }^{14} \mathrm{CO}$ production by neurons in vitro. CO release parallels endogenous cyclic GMP concentrations with its peak at the immature stage of neuronal differentiation in culture. Cyclic GMP production is inhibited by zinc protoporphyrin- 9 and zinc deuteroporphyrin IX 2,4-bis glycol, inhibitors of heme oxygenase, indicating that $\mathrm{CO}$ is an endogenous regulator of soluble guanylyl cyclase activities in these cells. Transforming growth factor- $\beta 2$, an olfactory neurogenic factor, specifically shows a negative effect on $\mathrm{CO}$ release in olfactory receptor neurons. These results indicate that $\mathrm{CO}$ may serve as a gaseous neuronal messenger linked to cyclic GMP production and suggests its involvement in developmental processes of the olfactory receptor neuron.

[Key words: heme oxygenase, carbon monoxide, cyclic GMP, second messenger, olfaction, transforming growth factor- $\beta$ ]

Recent evidence suggests that $\mathrm{CO}$, a chemically stable gas, may function as a messenger molecule in the CNS (Marks et al., 1991; Glaum and Miller, 1993; Maines et al., 1993; Stevens and

\footnotetext{
Received Apr. 20, 1995, revised Aug. 8, 1995; accepted Aug. 14, 1995.

We thank M. Angelyn Bethel for cell culture preparation, Julia Cheng for cGMP radioimmunoassay, and Lana Kramer for manuscript preparation. We also thank Dr. Daniel V. Madison for making available his unpublished results. T.I. is a Postdoctoral Fellow for Research Abroad supported by Japan Society for the Promotion of Science and TOYOBO Biotechnology Foundation (Japan) G.V.R. is supported by a McKnight Scholars Award, a grant from the Whitehall Foundation, the W. M. Keck Foundation, and NIH Grant 1RO1-DC01704.

Correspondence should be addressed to Dr. Gabriele V. Ronnett, Department of Neuroscience, The Johns Hopkins University School of Medicine, 725 North Wolfe Street, Baltimore, MD 21205.

Copyright $\odot 1995$ Society for Neuroscience $0270-6474 / 95 / 158214-09 \$ 05.00 / 0$
}

Wang, 1993; Zhuo et al., 1993). Like NO, CO can bind to the iron in heme and activate guanylyl cyclase (Brüne and Ullrich, 1987; Gräser et al., 1990; Furchgott and Jothianandan, 1991). Heme oxygenase (HO), which degrades heme to biliverdin and in the process releases CO (Maines, 1988; Marks et al., 1991; Schmidt, 1992), consists of two homologous isozymes. While type 1 (HO-1) is induced by heme and is most abundant in the spleen and in other peripheral tissues, type 2 (HO-2) is the constitutive form which is expressed at high levels in the brain (Cruse and Maines, 1988; Maines, 1988; Sun et al., 1990). By in situ hybridization and immunohistochemistry, discrete neuronal localization of HO-2 throughout the brain has been demonstrated (Ewing and Maines, 1992; Verma et al., 1993). In fact, the localization of $\mathrm{HO} 2$ by in situ hybridization more closely overlaps the localization of soluble guanylyl cyclase than does the localization of nitric oxide synthase (NOS) (Verma et al., 1993). In addition to HO-2, the enzymes responsible for heme biosynthesis and degradation, during which $\mathrm{CO}$ is released, have recently been identified in the brain (Verma et al., 1993).

Several studies have implicated $\mathrm{CO}$ in various physiological functions. Like NO, CO has been implicated as a candidate retrograde messenger for long-term potentiation (LTP) since the HO inhibitors, zinc protoporphyrin-9 (ZnPP-9) and zinc deuteroporphyrin IX 2,4-bis glycol (ZnBG) block the induction of LTP in hippocampal slices (Stevens and Wang, 1993; Zhuo et al., 1993). Additionally, long-lasting increases in amplitudes of evoked potentials are seen when $\mathrm{CO}$ is applied concomitantly with weak tetanic stimulation (Zhuo et al., 1993). The chemosensors of the carotid body may also be affected by $\mathrm{CO}$. These chemosensors are activated by molecular oxygen and inhibited by $\mathrm{CO}$ (Gonzalez et al., 1992). It has recently been demonstrated that the carotid body has high levels of HO-2 immunoreactivity, and ZnPP-9 markedly enhances chemosensory discharges in the carotid body (Prabhakar et al., 1995). Other investigators (Meffert et al., 1994), however, have failed to demonstrate a role for $\mathrm{CO}$.

Within this controversy is the fact that direct evidence for the physiological generation of $\mathrm{CO}$ by neurons is lacking. Furthermore, CO would need to be produced at significant enough concentrations so as to affect soluble guanylyl cyclase activity. In vitro studies demonstrate that $\mathrm{NO}$ is at least 30 -fold more potent at activating soluble guanylyl cyclase than $\mathrm{CO}$ (Stone and Marletta, 1994). Thus, in cell systems expressing both HO and NOS, it may be difficult to assess the role of $\mathrm{CO}$. An in vitro neuronal cell system expressing high levels of HO activity but in which NOS activity is essentially absent, would be useful in assessing the physiological generation of $\mathrm{CO}$ and its function. 
We have selected the olfactory receptor neuron as a model to examine the role of $\mathrm{CO}$ production by neurons for several reasons. First, recent evidence suggest that olfactory receptor neurons have a high level of expression of $\mathrm{HO}-2$ but lack NOS activity (Verma et al., 1993), which provides us with an ideal model in which to detect the amount of physiological CO production and to explore its effect on guanylyl cyclase activity. Second, high levels of heme-synthesizing enzymes are expressed in the olfactory receptor neuron (Verma et al., 1993). This suggests that olfactory receptor neurons possess a source for endogenous production of $\mathrm{CO}$. In addition, the olfactory epitheli$1 \mathrm{Im}$ is an excellent model for the study of neuronal differentiation. It is unique in the adult mammalian nervous system in that it is a site of ongoing neurogenesis (Graziadei and Graziadei, 1978). Recently, studies have used the development of the olfactory epithelium as a model to demonstrate that NO is transiently expressed during olfactory receptor neuron development (Bredt and Snyder, 1994; Roskams et al., 1994). Since neuronal NOS is absent from the adult system (Roskams et al., 1994), it may be that another messenger such as $\mathrm{CO}$ is important in olfactory receptor neuronal maturation. Recent studies have demonstrated that neurogenesis can take place in cultures of olfactory epithelium (Calof and Chikaraishi, 1989; Pixley, 1992), and it has been observed that interplay between several peptide growth factors modulate the proliferation and differentiation of olfactory epithelium cells (Mahanthappa and Schwarting, 1993; DeHamer et al., 1994). Transforming growth factor- $\beta 2$ (TGF$\beta 2$ ) is known to be a neurogenic factor which initiates terminal maturation of olfactory receptor neurons (Mahanthappa and Schwarting, 1993). In this study we utilize ${ }^{14} \mathrm{C}$-glycine to metabolically label endogenous heme and directly measure the physiological production of $\mathrm{CO}$ by these olfactory receptor neuronal cultures. We then go on to investigate the role of $\mathrm{CO}$ in cyclic GMP (cGMP) regulation during the maturation of these olfactory receptor neurons in culture.

\section{Material and Methods}

Bulbectomy procedure. Adult Sprague-Dawley rats were anesthetized with Xylaket (25\% ketamine, $2.5 \%$ xylazine in $15 \%$ ethanol, $0.9 \%$ saline) and fixed in a stercotaxic apparatus during surgery. For unilateral bulbectomies, the right olfactory bulb was exposed via a partial dorsal craniotomy and ablated by suction. Care was taken to avoid damage to the contralateral (left) olfactory bulb. The ablation cavity was filled with gelfoam to prevent invasion of frontal cortex neurons into this cavity which could provide an alternative target for regenerating olfactory axons. The skin above the lesion was sutured and animals were allowed to recover from anesthesia under a heat lamp. The degree of lesion was visually and microscopically verified. In all cases reported it was complete or supercomplete (extending into the olfactory peduncle). Following recovery from anesthesia, rats were returned to the animal colony and maintained on a normal diet until killed at $3 \mathrm{~d}$, and 1,2, and 3 weeks post-bulbectomy.

Preparation of antisera. Several antisera specific for $\mathrm{HO}-2$ were utilized. In the first case, a polyclonal antibody specific for HO-2 was generated against a peptide based on amino acids 247-258 of HO-2 protein conjugated to bovine serum albumin (Prabhakar et al., 1995). The antibody was then affinity purified using a column consisting of thyroglobulin-HO-2 peptide conjugate immobilized on $\mathrm{CNBr}$-activated sepharose. This antibody has been shown to specifically react with a band in brain extracts with a relative mobility of $36 \mathrm{kDa}$ (Prabhakar et al., 1995).

A second commercially available rabbit polyclonal antibody to $\mathrm{HO}-2$ (Stressgen) was utilized to confirm the immunohistochemical localization of HO-2. This antisera reacted with a band in brain extracts with a relative mobility of $36 \mathrm{kDa}$ (data not shown). Immunoreactivity with this band was blocked by preabsorption of the antibody with its antigen (data not shown). Purified rat testes HO-2 was used as the immunogen.
For antibodies to soluble guanylyl cyclase, two different peptide se quences were used. Peptides based on amino acids 340-359 and amino acids $469-485$ of the $\beta-1$ subunit of the soluble guanylyl cyclase were synthesized and conjugated to bovine serum albumin and used as inmunogens for injection into rabbits. Antibodies 1136 (directed against a 340-359) and 1139 (directed against a 469-485) were purified using a column consisting of the guanylyl cyclase peptide coupled to Atti-gel 10 (Bio-Rad). Immunoblot analyses demonstrated that each antiserum specifically recognized a $70 \mathrm{kDa}$ band in the brain and in peripheral tissues (data not shown). Immunoreactivity in each case was blocked when the antibodies were pre-absorbed by their specific peptide (data not shown).

Immunohistochemistry. Adult Sprague-Dawley rats were anesthetized with pentobarbital and perfused with saline, followed by $4 \%$ freshly depolymerized paraformaldehyde in $0.1 \mathrm{M}$ phosphate-buffered saline (PBS) $\mathrm{pH}$ 7.4. The olfactory tissue was then dissected and fixed again for $2 \mathrm{hr}$ with 4\% paraformaldehyde in PBS. After fixation, all tissue was bathed in 10\% sucrose in PBS to cryoprotect, and then transferred to plastic molds and imbedded in OCT medium (Tissue-Tek) on dry ice. Sections $(12 \mathrm{~mm})$ were cut on gelatin-coated glass slides, thawmounted, dried, and stored at $-70^{\circ} \mathrm{C}$. For immunohistochemistry, sections were blocked for $1 \mathrm{hr}$ in PBS containing $4 \%$ normal goat serum, and then incubated overnight at $4^{\circ} \mathrm{C}$ in PBS containing $1 \%$ normal goat serum and the affinity-purified antibody. The anti-HO-2-peptide antibody was used at a dilution of 1:100, and the anti-HO-2 antibody was used at a dilution of 1:2000. The anti-soluble guanylyl cyclase antibody 1136 and 1139 were used at dilutions of 1:300.

Horseradish peroxidase staining was performed using an avidin-biotin-peroxidase kit (Elite kit, Vectastain). Sections incubated with either preimmune serum or affinity-purified antibody preabsorbed with the appropriate antigen, showed no staining using identical incubation and development conditions (data not shown).

${ }^{14} \mathrm{CO}$ measurement. Primary cultures of olfactory receptor neurons were prepared from neonatal rats as previously described (Ronnett et al., 1991), and cultured in slide flasks at a density of $1 \times 10^{6}$ cells per $\mathrm{cm}^{2}$. These cultures contained less than $1 \%$ glial contaminants (Ronnett et al., 1991). On each culture day, slide flasks were preincubated with $5 \mu \mathrm{Ci} 2{ }^{14} \mathrm{C}$-glycine for $5 \mathrm{hr}$, and then the radioactivity incorporated into ${ }^{14} \mathrm{CO}$ was measured as described (Lincoln et al., 1989). Brieffy, the gases from cultured flasks were drawn through the following series of traps: ethanolamine-methanol (trap for $\left.\mathrm{CO}_{2}\right), \mathrm{H}_{2} \mathrm{SO}_{4}, \mathrm{CaCl}_{2}$, heated hopcalite, and ethanolamine-methanol (trap for $\mathrm{CO}$ ). ${ }^{14} \mathrm{CO}$ was converted to ${ }^{14} \mathrm{CO}_{2}$ by hopcalite and collected in the second ethanolamine-methanol trap. Each trapping solution was counted. The proportion of released ${ }^{14} \mathrm{CO}$ compared to ${ }^{14} \mathrm{CO}$, ranged from 2 to $17 \%$. No radioactivity over background $(30 \mathrm{cpm})$ was detected in the $\mathrm{CO}$ trap when hopcalite was removed from the series of traps. When inhibitors were used, cultures were incubated with ${ }^{14} \mathrm{C}$-glycine in the presence of $7 \mathrm{nPP}-9,7 \mathrm{nBG}$, or nitroarginine methyl ester (NAME) at the indicated concentrations for $5 \mathrm{hr}$, after which time the gases were drawn from the flasks.

In the growth factor experiment, primary cultures of neonatal rat olfactory receptor neurons were plated as described previously, except that the cells were plated in a medium which did not contain exogenous growth factors. Approximately $6 \mathrm{hr}$ after cell plating, the feeding medium was replaced with fresh medium containing $10 \mathrm{ng} / \mathrm{ml}$ of the peptide growth factors. Cultures were maintained for $1-5 \mathrm{~d}$, at which time ${ }^{14} \mathrm{CO}$ production was measured as previously described to determine the effect of each peptide growth factor. For dose-response curves, cultures were treated similarly on day 3 , except that varying concentrations of TGF- 32 were added to the cultures. Combination with $50 \mathrm{ng} / \mathrm{ml}$ antinerve growth factor (anti-NGF) was also tried to get rid of any endogenous NGF effect; however, no significant change was observed (data not shown). TGF- $\beta 2$ was obtained from Genzyme and other growth factors were from Collaborative Biochemical Products.

cGMP measurement. Neonatal primar y cultures of olfactory receptor neurons were plated at a density of $1 \times 10^{\circ}$ cells per $\mathrm{cm}^{2}$ in 24-well cluster dishes and maintained $1-4 \mathrm{~d}$ in culture. When inhibitors were used, cultures were incubated with / $\mathrm{nPP}-9$ or $0.1 \mathrm{mM}$ NAME for 30 min; control cells were incubated with a mock buffer for $30 \mathrm{~min}$. Cell monolayers were harvested in a $6 \%$ trichloroacetic acid solution and cGMP was quantitated by radioimmunoassay (Amersham). In the conditioned media experiment, donor cells were preincubated with or without the indicated concentration of ZnBG for 20 min on culture day 3 , and the media was transferred to the recipients. After 5 min, isobutylmethylxanthine (IBMX) was added, and after an additional 5 min, 


\section{HO-2}
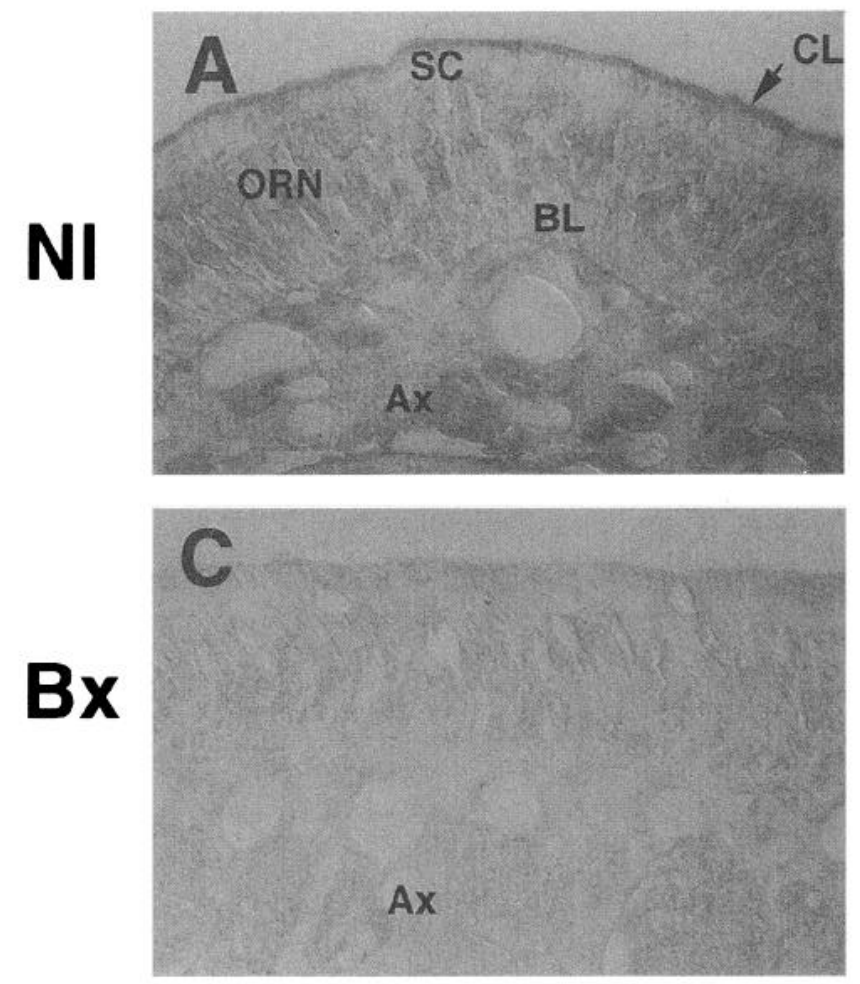

sGC
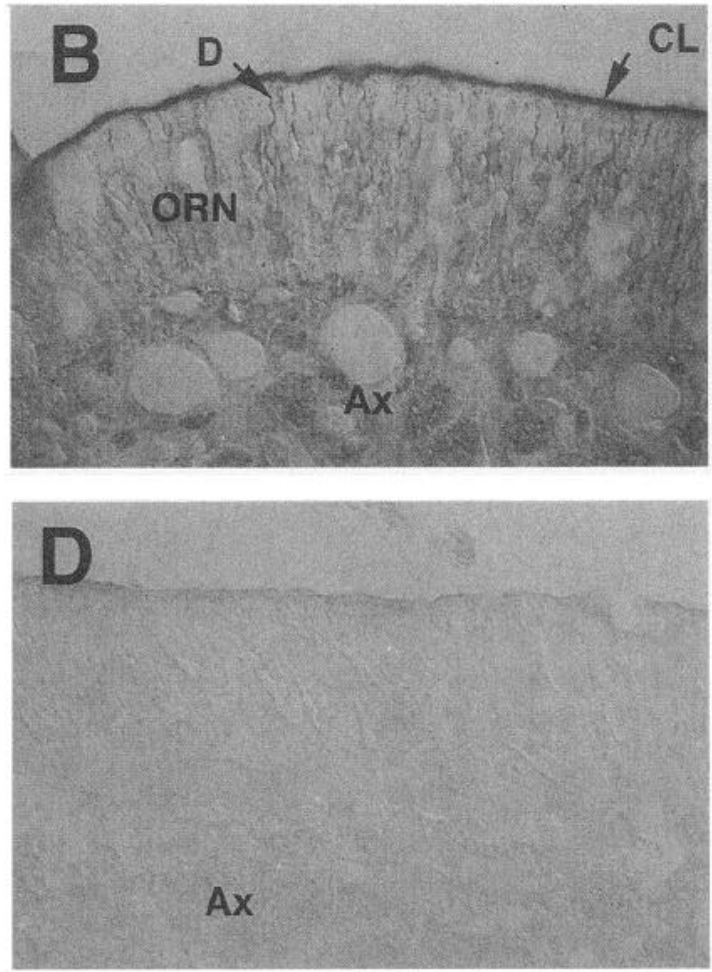

Figure 1. Colocalization of HO-2 and soluble guanylyl cyclase in olfactory neuroepithelium. Coronal sections of normal adult olfactory neuroepithelium $(A$ and $B)$ and of adult olfactory epithelium three days post-bulbectomy $(C$ and $D$ ) were immunostained with affinity-purified antibodies to HO-2 $(A$ and $C)$ and to soluble guanylyl cyclase $(s G C)(B$ and $D)$. Immunoreactivity for HO-2 is detected in the olfactory receptor neuronal $(O R N)$ cell body, the apical ciliary layer $(C L)$ and in axon bundles $(A x)$. Notably, immunoreactivity is absent from the sustentacular cell layer $(S C)$ and from the most immature olfactory receptor neuron in the basal layers of the epithelium $(B L)$. Soluble guanylyl cyclase immunoreactivity $(B)$ is localized to essentially identical structures, including the olfactory receptor neuron cell layer $(O R N)$, the ciliary layer $(C L)$, and axon bundles $(A x)$. In addition, striking immunoreactivity is seen in dendritic processes $(D)$ and at all levels of olfactory receptor neuron maturity. Round vacuolarlike structures represent blood vessels cut in cross section. Olfactory bulbectomies cause retrograde degeneration of olfactory receptor neurons. Staining was performed $3 \mathrm{~d}$ after bulbectomy to demonstrate that when olfactory receptor neurons degenerate and are removed from the epithelium; immunoreactivity for HO-2 $(C)$ and soluble guanylyl cyclase $(D)$ is absent, confirming their localization to olfactory receptor neurons.

cGMP was assayed. Control concentrations of cGMP in this experiment were $23 \mathrm{pmol} / \mathrm{mg}$ of protein, which is relatively high due to the IBMX treatment.

Reverse transcriptase-polymerase chain reaction (RT-PCR). Primary cultures of olfactory receptor neurons were maintained in a feeding medium with/without $10 \mathrm{ng} / \mathrm{ml}$ TGF- $\beta 2$. On day 3 , poly(A) RNA was prepared from cultured olfactory receptor neurons. cDNA was synthesized in a $50 \mu \mathrm{l}$ reaction utilizing $1 \mu \mathrm{g}$ of poly(A) RNA. The RNA mixed with $100 \mathrm{ng}$ oligo(dT) primer was denatured for $10 \mathrm{~min}$ at $70^{\circ} \mathrm{C}$ and cooled to $37^{\circ} \mathrm{C}$. Reverse transcription was performed at $37^{\circ} \mathrm{C}$ for 1 hr after addition of $10 \mu \mathrm{l}$ of $5 \times$ reverse transcription buffer (BRL), 5 $\mu \mathrm{l}$ of $0.1 \mathrm{~m}$ DTT, $2 \mu \mathrm{l}$ of $2.5 \mathrm{~mm}$ dNTPs, $20 \mathrm{U}$ of RNasin, $2 \mu \mathrm{l}$ of MMLV reverse transcriptase (Superscript, BRL). After first-strand cDNA synthesis, HO-2 and $\beta$-actin PCR products were generated from these cDNA's; $5 \mu \mathrm{l}$ of cDNA was utilized as template in subsequent 50 $\mu$ I PCRs. PCR amplifications were performed 30 cycles with following specific oligo primers $(0.5 \mu \mathrm{M})$; $\mathrm{P} 16$ and $\mathrm{P} 17$ for HO-2, Act-5 and Act-3 for $\beta$-actin. Under the condition used, PCR products increased linear between $28-33$ cycles.

Oligonucleotides used as PCR primers were synthesized from the following positions in the cDNAs. HO-2 (Rotenberg et al., 1990): P16 $=5^{\prime}$-CACTTGGGATAGGATGCAAACAAC- $3^{\prime}$ (984-961 on cDNA), P17 $=5^{\prime}$-TTTGAATGAGCCAAGGACCGAAGTG- $3^{\prime}(-49$ to -25 on cDNA). Predicted size of PCR products with P16 and P17 is $1033 \mathrm{bp}$. $\beta$-Actin (Nudel et al., 1983): Act-5 = 5'-ATGGATGACGATATCGCTGCGCTC-3' (1242-1265 on gene), Act-3 = 5'-GGCCAGGATAGAGCCACCAATCCA-3' (3045-3022 on gene). Predicted size of PCR products with Act-5 and Act-3 is 1042 bp.

\section{Results}

Colocalization of $\mathrm{HO}-2$ and soluble guanylyl cyclase immunoreactivities in the adult olfactory neuroepithelium

A necessary prerequisite for a functional role of $\mathrm{HO}$ as a mediator of guanylyl cyclase activity is the expression of these proteins in olfactory receptor neurons. For this reason, immunohistochemistry was performed using affinity-purified anti-peptide antibodies directed against rat HO-2 and the $\beta_{1}$ subunit of rat soluble guanylyl cyclase. HO-2 immunoreactivity was detected in the olfactory receptor neuron of the adult olfactory neuroepithelium (Fig. 1A). Immunoreactivity was seen in the cilial layer in the pseudostratified layer of olfactory receptor neuron cell bodies, and in the axon bundles in the submucosal region. No staining was apparent in the sustentacular cell layer located superficially in the neuroepithelium. In addition, there was no immunoreactivity in the most basally located cells, which represent the most immature olfactory receptor neurons. Soluble guanylyl cyclase immunoreactivity has nearly an identical pattern (Fig. 1B). In this case, immunoreactivity was seen in the cilial layer, in the olfactory receptor neuron cell body layer, and in axon bundles. Immunoreactivity was also seen prominently in dendritic processes. A subtle difference exists between the 

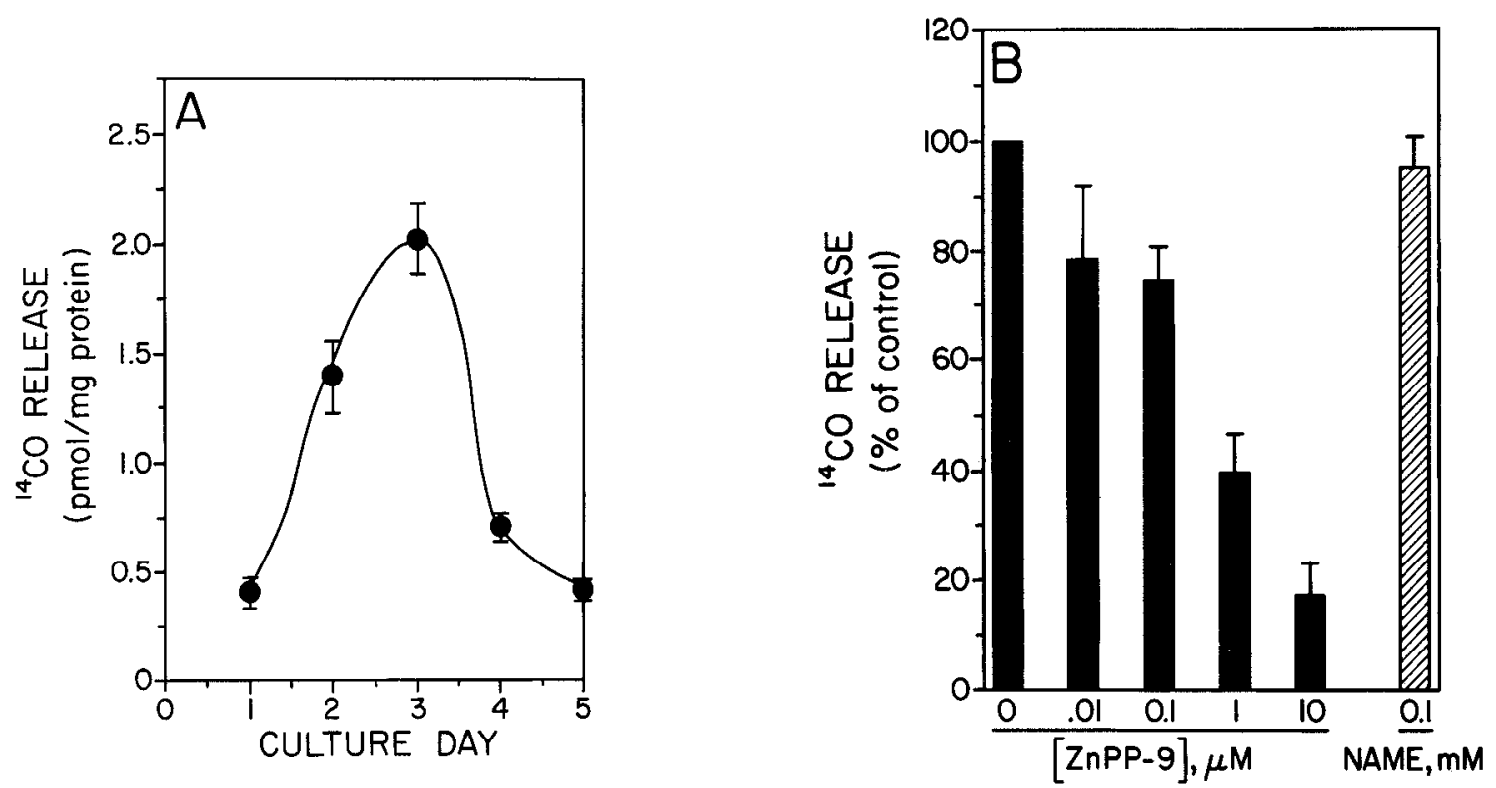

Figure 2. CO production in primary cultures of olfactory receptor neurons. Primary cultures of olfactory receptor neurons were prepared as described and used for ${ }^{14} \mathrm{CO}$ release from 1 to $5 \mathrm{~d}$ in culture. On each culture day, cultures in slide flasks were preincubated with $5 \mu \mathrm{Ci} 2 \mathrm{I}^{14} \mathrm{C}$ glycine for $5 \mathrm{hr}$ and the radioactivity incorporated into ${ }^{14} \mathrm{CO}$ was measured. $A$, Time course of $\mathrm{CO}$ production in rat olfactory receptor neurons in culture. ${ }^{11} \mathrm{CO}$ production changes dramatically in culture, peaking during the lime of neurite outgrowth, although ${ }^{11} \mathrm{CO}_{2}$ production is constant every culture day (data not shown). Data are presented as the mean of 4-10 independent experimental determinations \pm SEM. $B$, Effect of inhibitors on $\mathrm{CO}$ production in primary cultures of olfactory receptor neurons on day $3 .{ }^{14} \mathrm{CO}$ production is inhibited by ZnPP-9, but unaffected by NAME. $\angle n B G$ inhibited ${ }^{14} \mathrm{CO}$ production in a manner similar to that of $\angle \mathrm{nPP}-9$ (1 $\mathrm{MM} \angle \mathrm{nBG}$ inhibited ${ }^{14} \mathrm{CO}$ production to $41 \pm 3.2 \%$ of control).

immunolocalizations for $\mathrm{HO}-2$ and soluble guanylyl cyclase in that soluble guanylyl cyclase immunoreactivity was observed extending down to olfactory receptor neurons and to precursor cells at the basal lamina.

Ablation of the olfactory bulb results in retrograde degeneration of the olfactory receptor neurons over a 1 week period (Margolis et al., 1974). Large vacuoles develop in the regions of axon bundles. As olfactory receptor neurons degenerate, neuronal markers normally associated with olfactory receptor neurons disappear from the neuroepithelium. Three days after bulbectomy, HO-2 immunoreactivity (Fig. 1C) and soluble guanylyl cyclase immunoreactivily (Fig. 1D) significantly decreased, further confirming their localization to olfactory receptor neurons. Residual staining in the olfactory receptor neuronal layer represents olfactory receptor neuronal cell bodies which have not yet degenerated by three days after bulbectomy. Thus, $\mathrm{HO}-2$ is appropriately located to affect soluble guanylyl cyclase activity.

\section{CO production by olfactory receptor neurons}

To investigate the generation of $\mathrm{CO}$ by neurons, primary cultures of olfactory receptor neurons were used. In addition to $\mathrm{HO} 2$, olfactory receptor neurons contain a high density of heme-metabolizing enzymes such as $\delta$-aminolevulinate synthase (ALAS) and cytochrome P-450 reductase (CPR) (Verma et al., 1993). Since the colocalization of ALAS with HO-2 in the receptor neurons indicates that the machinery for porphyrin turnover and CO biosynthesis occur together (Verma et al., 1993), olfactory receptor neurons were incubated with $2-{ }^{14} \mathrm{C}$-glycine, a heme precursor, to label $\mathrm{CO}$ produced by $\mathrm{HO}-2$. Five hours after the addition of ${ }^{14} \mathrm{C}$-glycine, ${ }^{14} \mathrm{CO}$ resulting from heme metabolism was measured in these cell cultures (Landaw and Winchell, 1966; Lincoln et al., 1989). As shown in Figure $2 A$, there is a sharp increase of ${ }^{14} \mathrm{CO}$ release, from $0.41 \pm 0.07 \mathrm{pmol} / \mathrm{mg}$ protein at day 1 in culture, to $2.0 \pm 0.16 \mathrm{pmol} / \mathrm{mg}$ protein at day 3 .
To determine the total amount of CO production, cellular uptake of ${ }^{14} \mathrm{C}$-glycine was measured in cultures. Under the condition used, cellular uptake of ${ }^{14} \mathrm{C}$-glycine remained linear for 5 $\mathrm{hr}$ and the average concentration of ${ }^{14} \mathrm{C}$-glycine for this period in the cells was determined to be 380 pmol/mg protein. Taking into account the ratio of ${ }^{14} \mathrm{C}$-glycine to the total endogenous glycine levels in neuronal cells $(20 \mathrm{nmol} / \mathrm{mg}$ protein) (Hall et al., 1979; Freeman et al., 1983), the total amount of $\mathrm{CO}$ production from glycine at day 3 is estimated to be approximately $100 \mathrm{pmol} / \mathrm{mg}$ protein. Afterwards ${ }^{14} \mathrm{CO}$ release falls rapidly and returns to the previous levels by days 4 and 5 . This peak in ${ }^{14} \mathrm{CO}$ production parallels the time during which neurite extension is occurring in culture (Ronnett et al., 1991). The level of HO activity in olfactory receptor neurons is the highest when it is compared to those of other brain regions (Verma et al., 1993), making the production of $\mathrm{CO}$ by olfactory receptor neurons robust. In contrast, ${ }^{14} \mathrm{C}$-carbon dioxide $\left({ }^{14} \mathrm{CO}_{2}\right)$ production was constant (data not shown).

To determine the pathway of CO generation, ZnPP-9, a potent inhibitor of HO function, was utilized (Maines, 1981; Stevens and Wang, 1993). ZnPP-9 lowered ${ }^{14} \mathrm{CO}$ release, with half-maximal inhibition occurring at $0.2 \mu \mathrm{M}$ ZnPP-9 (Fig. 2B). ZnBG, another potent inhibitor of $\mathrm{HO}$ (Schuman and Madison, 1991b; Vreman et al., 1991), inhibited ${ }^{14} \mathrm{CO}$ production in a manner similar to that of $\mathrm{ZnPP}-9$ ( $1 \mu \mathrm{M} \mathrm{ZnBG}$ inhibitcd ${ }^{14} \mathrm{CO}$ production to $41 \pm 3.2 \%$ of control). These results indicate that ${ }^{14} \mathrm{CO}$ is generated predominantly from heme breakdown by $\mathrm{HO}$ in the olfactory receptor neuron, which agrees with the previous finding that $\mathrm{HO}$ is the predominant pathway of heme degradation in vivo (Lincoln et al. 1989). On the other hand, nitroarginine methyl ester (NAME), a potent inhibitor of NOS, failed to significantly alter ${ }^{14} \mathrm{CO}$ release, in spite of the similarities between NOS and CPR (Fig. 2B). 

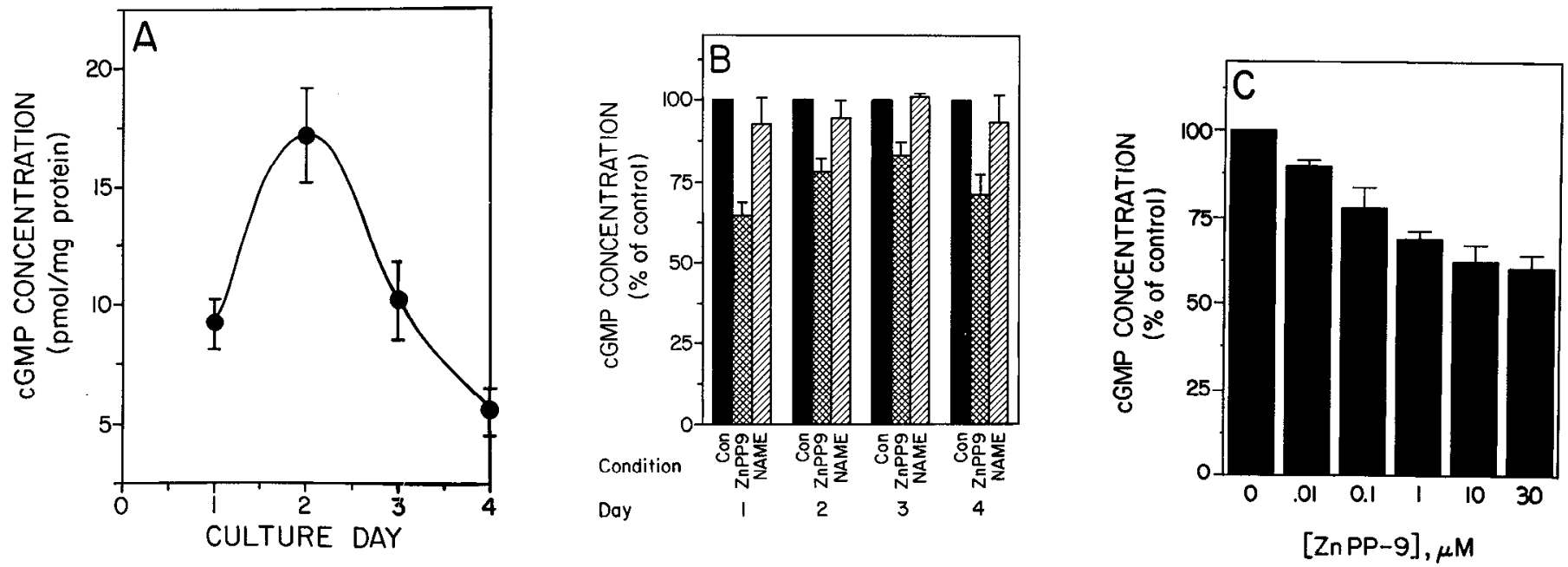

Figure 3. cGMP levels in primary cultures of olfactory receptor neurons. Primary cultures of olfactory receptor neurons were prepared as described. Over days 1-4 in culture, cGMP levels werc assaycd by radioimmunoassay. A, Time course of endogenous cGMP concentration. cGMP levels change over time, increasing to a maximum at day 2 in culture which parallels CO production and neurite outgrowth. Data are presented as the mean of five to six independent experimental determinations \pm SEM. $B$, Effect of ZnPP-9 and NAME on cGMP concentration over time in culture. ZnPP-9 at a concentration of $1.0 \mu \mathrm{M}$ significantly lowers cGMP concentrations, whereas $0.1 \mathrm{mM}$ NAME has little effect. $C$, Dose-response curve of ZnPP-9 effect on cGMP concentrations. ZnBG lowered cGMP concentrations in a manner similar to ZnPP-9 ( $1 \mu \mathrm{M} Z \mathrm{ZnBG}$ lowered cGMP levels to $73.2 \pm 2.3 \%$ of control). $\mathrm{ZnPP}-9$ and $\mathrm{ZnBG}$ lower cGMP levels with the same $\mathrm{IC}_{50}$ as their effect on ${ }^{14} \mathrm{CO}$ production.

\section{CO regulates cGMP levels in olfactory receptor neurons}

$\mathrm{CO}$ is known to be an activator of soluble guanylyl cyclase (Brüne and Ullrich, 1987; Gräser et al., 1990; Furchgott and Jothianandan, 1991). Recent evidence suggests that CO may function as an endogenous regulator of soluble guanylyl cyclase in the brain (Marks et al., 1991; Maines et al., 1993; Verma et al., 1993). In contrast to discrepancies in the localizations of NOS and guanylyl cyclase in the brain, guanylyl cyclase localization is virtually identical to that of $\mathrm{HO}-2$ in numerous brain regions (Verma et al., 1993). Because olfactory receptor neurons contain large concentrations of $\mathrm{HO}-2$ and soluble guanylyl cyclasc, wc directly determined that $\mathrm{CO}$ is a mediator of cGMP production in these cells.

To determine whether the CO generated by $\mathrm{HO}$ is a physiological messenger in olfactory receptor neurons, cGMP levels and the effects of ZnPP-9 on cGMP levels were monitored over time in olfactory receptor neuron cultures. As shown in Figure $3 A$, there is an increase of endogenous cGMP from $9.2 \pm 0.94$ pmol/mg protein level in day 1 . After the peak of $17 \pm 1.9$

\section{Table 1. Conditioned media transfer experiment}

Treatment of

\begin{tabular}{llc}
$\begin{array}{l}\text { recipient } \\
\text { cells } \\
\text { with } \mathrm{ZnBG}\end{array}$ & $\begin{array}{l}\text { Addition of } \\
\text { donor media }\end{array}$ & $\begin{array}{l}\text { cGMP in } \\
\text { recipient cells } \\
\text { (\% of control) }\end{array}$ \\
\hline No & No & $100 \pm 2.6^{c}$ \\
No & Yes & $95.7 \pm 3.4$ \\
Yes & No & $60 \pm 1.7$ \\
Yes & Yes & $88.7 \pm 3.4$ \\
Yes & Yes $(\mathrm{ZnBG})^{b}$ & $53.9 \pm 5.2$
\end{tabular}

a On culture day 3 , donor cells were preincubated with or without $\mathrm{ZnBG}$ for $15 \mathrm{~min}$, and the media were transferred to the recipients. After $5 \mathrm{~min}$ isobutylmethylxanthine was added, and after an additional 5 min cGMP was assayed.

${ }^{b}$ Donor cells were preincubated with $1 \mu \mathrm{M} \mathrm{ZnBG}$ in this trial.

Control concentrations of cGMP were $23 \mathrm{pmol} / \mathrm{mg}$ of protein. $\mathrm{pmol} / \mathrm{mg}$ protein on day 2, cGMP levels fall to their lowest level by day 4 . The change in cGMP concentration essentially parallels that of $\mathrm{CO}$ releasc. Furthermore, on cach day, $1 \mu \mathrm{M}$ ZnPP-9 significantly lowers endogenous cGMP, which agrees with its ability to act as an inhibitor of $\mathrm{HO}$ activity (Fig. 3B). $A$ dose-response curve was generated for the inhibitory effect of ZnPP-9 on cGMP levels in these cells (Fig. 3C). As with the effect of $\mathrm{ZnPP}-9$ on ${ }^{14} \mathrm{CO}$ release, half-maximal inhibition occurs at a concentration $0.2 \mu \mathrm{M} \mathrm{ZnPP}-9$. In addition, $\mathrm{ZnBG}$ lowered cGMP concentrations in a manner similar to ZnPP-9 (1 $\mu \mathrm{M}$ $\mathrm{ZnBG}$ lowered cGMP levels to $73.2 \pm 2.3 \%$ of control). On the other hand, 0.1 mM NAME did not show a significant effect on cGMP levels, also in agreement with its inability to affect $\mathrm{CO}$ release (Fig. $2 B$ ). Although there are several assays for NOS activity, the use of NAME to identify an NO-mediated cGMP component is considered to be among the most sensitive. This result of NAME treatment confirms the previous finding that olfactory receptor neurons do not contain detectable levels of NOS (Verma et al., 1993).

In preparations of purified and reconstituted enzymes, studies suggest that HO inhibitors may act at the level of soluble guanylyl cyclase (Ignarro et al., 1984), which would potentially confound our results. To determine whether these HO inhibitors are acting at the level of guanylyl cyclase, we previously conducted conditioned media transfer experiments with ZnPP-9 (Verma et al., 1993) and now with an additional inhibitor of $\mathrm{HO}, \mathrm{ZnBG}$. In media transfer experiments, as shown in Table 1 , recipient cells treated with $1 \mu \mathrm{M}$ ZnBG had low levels of cGMP (60 $1.7 \%$ of control). Addition of conditioned media from donor cells to recipient cells treated with ZnBG elevated cGMP levels $(88.7 \pm 3.4 \%)$. Thus, ZnBG cannot act at the level of soluble guanylyl cyclase, as donor medium which provides $C O$ can elevate cGMP levels. In addition, when donor cells were preincubated with $\mathrm{ZnBG}$ and then the media was transferred to recipient cells treated with $\mathrm{ZnBG}$, cGMP levels remained low $(53.9 \pm 5.2 \%)$. These results clearly indicate that these $\mathrm{HO}$ in- 

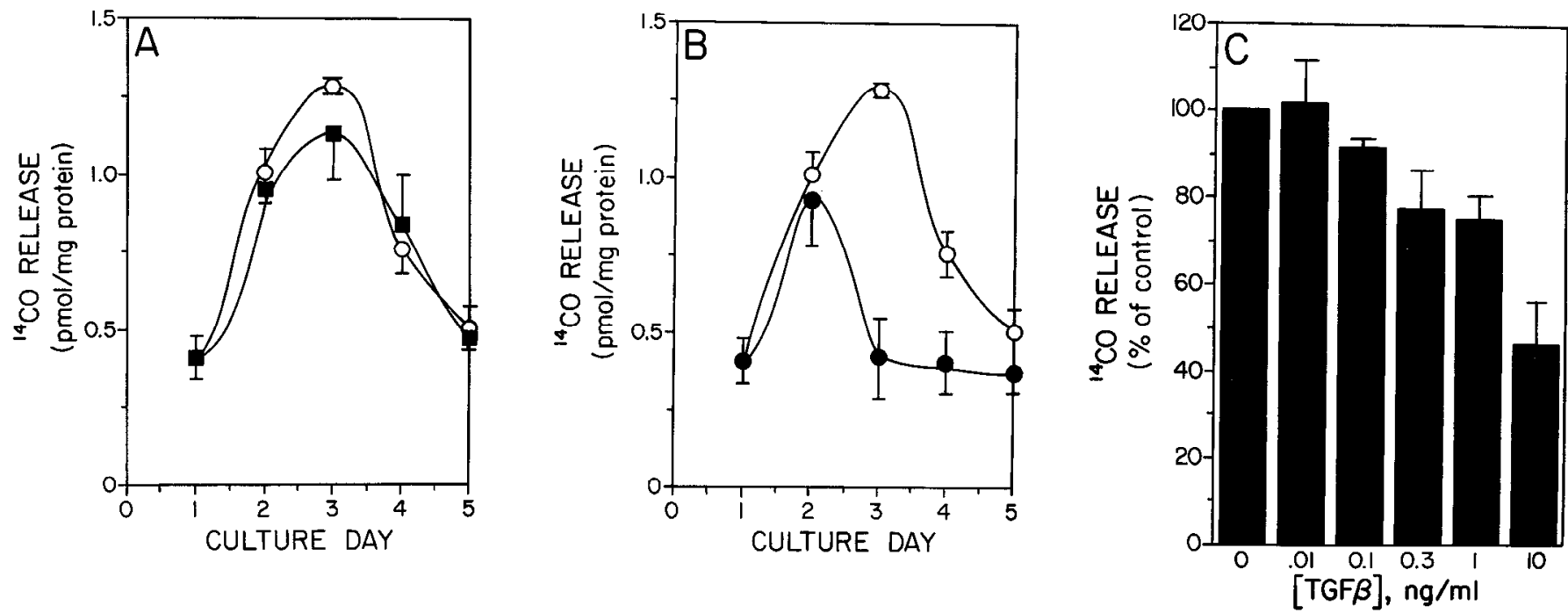

Figure 4. Effects of NGF and TGF- $\beta 2$ on CO production in primary cultures of olfactory receptor neurons. A, Effect of NGF on CO production (I) compared to control $(O)$ cultures. Approximately 6 hours after cell plating, the feeding medium was replaced with fresh medium containing no growth factor (control) or $10 \mathrm{ng} / \mathrm{ml}$ NGF to observe effects of NGF. There is little effect of NGF on ${ }^{14} \mathrm{CO}$ release. Cultures were maintained for $1-5 \mathrm{~d}$, at which time ${ }^{14} \mathrm{CO}$ production was measured. Data are presented as the mean of two independent experimental determinations. $B$, Effect of TGF- $\beta 2$ on CO production $(O)$ compared with control $(O)$ cultures. To observe the effect of TGF- $\beta 2$, feeding medium was replaced with medium containing $10 \mathrm{ng} / \mathrm{ml}$ TGF- $\beta 2$. TGF- $\beta 2$ treatment results in the suppression of ${ }^{14} \mathrm{CO}$ release to basal levels. $C$, Dose-response curve of TGF- $\beta 2$ effect on $\mathrm{CO}$ production on day 3 .

hibitors act on the $\mathrm{CO}$ generating cell (the level of $\mathrm{HO}$ ) but not on the responding cell (the level of guanylyl cyclase). Collectively, these results suggest that $\mathrm{CO}$ may be a physiological mediator of the changes in endogenous cGMP levels.

\section{Neuronal maturation induces a change in CO production}

Olfactory receptor neurons are continually replaced throughout adult life, making them a unique class of neurons (Graziadei and Graziadei, 1978) and an excellent model for the study of neuronal differentiation. Several cultured systems of olfactory receptor neurons or olfactory epithelium have been used to study this process in vitro (Calof and Chikaraishi, 1989; Pixley, 1992; Mahanthappa and Schwarting, 1993). Olfactory neurogenesis is a multistage process which includes the differentiation of basal cells into committed neuronal precursors, precursor proliferation, and differentiation of the precursors into postmitotic neurons (Calof and Chikaraishi, 1989). Recent studies have demonstrated that TGF- $\beta 2$ initiates terminal differentiation and promotes neurogenesis or survival in olfactory receptor neurons in culture, while epidermal growth factor (EGF) acts as a mitogen for the basal cell (Mahanthappa and Schwarting, 1993). In olfactory epithelium cultures, TGF- $\beta 2$ caused an increase in neuron cell adhesion molecule (N-CAM)-positive cells; N-CAM is a marker of olfactory neurogenesis (Calof and Chikaraishi, 1989; Mahanthappa and Schwarting, 1993).

As shown in Figure $2 A$, CO production changes dramatically during neuronal maturation in culture. In primary cultures, olfactory receptor neurons start to extend neurites at day 1 and a mature neuronal appearance is established by about day 4 (Ronnett et al., 1991). To investigate whether the CO signaling system may be involved in olfactory neurogenesis, the effects of TGF- $\beta 2$ and NGF on CO release were determined. Primary cultures of olfactory receptor neurons were plated in the presence or absence of $10 \mathrm{ng} / \mathrm{ml} \mathrm{NGF}$ or $10 \mathrm{ng} / \mathrm{ml} \mathrm{TGF}-\beta 2$, and ${ }^{14} \mathrm{CO}$ release was determined for days 1-5. As shown in Figure $4 A$, there is no significant difference in ${ }^{14} \mathrm{CO}$ release in the absence or presence of NGF. However, in the presence of TGF- $\beta 2$, the usual peak of ${ }^{14} \mathrm{CO}$ release at day 3 was significantly suppressed (Fig. $4 B$ ). The dose-dependent effect of TGF- $\beta 2$ on ${ }^{14} \mathrm{CO}$ was determined in the range of $0.01-10 \mathrm{ng} / \mathrm{ml}$ on day 3 , when the maximal effect of TGF- $\beta 2$ was seen (Fig. $4 C$ ). As shown in Figure 5, RT-PCR revealed that TGF- $\beta 2$ specifically suppresses the expression of messenger RNA of $\mathrm{HO}-2$ in cultures. Taking into account the very slow onset of TGF- $\beta 2$ 's effect, TGF- $\beta 2$ is likely to modulate $\mathrm{CO}$ production by reducing protein expression of HO-2 but not by inhibiting its enzymatic activity. TGF$\beta 2$ promotes differentiation of olfactory receptor neurons in these cultures at $10 \mathrm{ng} / \mathrm{ml}$ concentrations; this growth factor causes increased neurite outgrowth and an increased percentage of differentiated cells (Mahanthappa and Schwarting, 1993). The negative control of TGF- $\beta 2$ on CO release suggests that the physiologic role of CO production and cGMP production may be at earlier stages in olfactory neuronal development and differentiation.

The effects of various peptide growth factors were examined to determine the effect specificity of TGF- $\beta 2$ on $\mathrm{CO}$ release, (Fig. 6). Messenger RNA for NGF and brain-derived neurotrophic factor (BDNF) have been detected in the olfactory bulb (Guthrie and Gall, 1991). However, NGF, BDNF, and neurotrophin-3 only minimally lower ${ }^{14} \mathrm{CO}$ release (Fig. 6). In contrast to the effects of TGF- $\beta 2$, both EGF and TGF- $\alpha$ stimulate the proliferation of olfactory basal cells in vitro (Mahanthappa and Schwarting, 1993). EGF and TGF- $\alpha$ show intermediate suppression of ${ }^{14} \mathrm{CO}$ release (Fig. 6). Messenger RNA for basic fibroblast growth factor (bFGF) has been detected in the olfactory bulb (Ernfors et al., 1990) and intense immunoreactivity for platelet derived growth factor (PDGF) is seen around the olfactory neuron at all stages of development, from embryo to adult (Sasahara et al., 1992). Both bFGF and PDGF show intermediate suppression of ${ }^{14} \mathrm{CO}$ release. However, TGF- $\beta 2$ showed the highest suppression of ${ }^{14} \mathrm{CO}$ among all tested factors. This spec- 


\section{HO-2 B-ACTIN}

\section{TGF-ß}
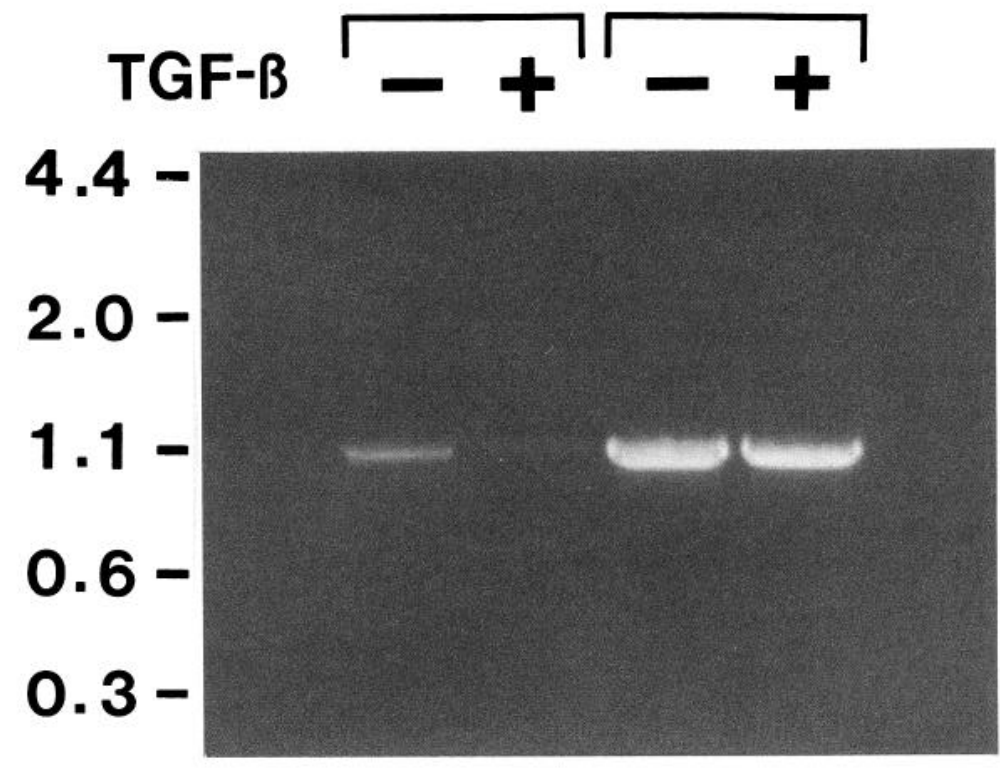

Figure 5. Effect of TGF- $\beta 2$ on $\mathrm{HO}-2$ mRNA in primary cultures of olfactory receptor neurons. Primary cultures of olfactory receptor neurons were maintained in a feeding medium containing no growth factor (control) or $10 \mathrm{ng} / \mathrm{ml}$ TGF- $\beta 2$. RNA was prepared from these cultured olfactory receptor neuron on day 3. RT-PCRs were performed using primers specific for $\mathrm{HO}-2$ and $\beta$-actin. The level of mRNA of $\mathrm{HO}-2$ in olfactory receptor neurons was significantly suppressed by the effect of TGF- $\beta 2$. The predicted sizes of PCR products of $\mathrm{HO}-2$ and $\beta$-actin are 1033 bp and 1041 bp each.

ificity of TGF- $\beta 2$ action also supports the direct involvement of ${ }^{14} \mathrm{CO}$ release in olfactory neural differentiation.

\section{Discussion}

The main findings of this study are that olfactory receptor neurons express HO-2 and soluble guanylyl cyclase and that the high levels of $\mathrm{CO}$ produced by the action of $\mathrm{HO}-2$ mediate cGMP levels in these cells. Abundant evidence has established a major role for $\mathrm{NO}$, a free radical gas that activates soluble guanylyl cyclase, as a messenger molecule in blood vessels, macrophages, and brain (Moncada et al., 1991). Although CO

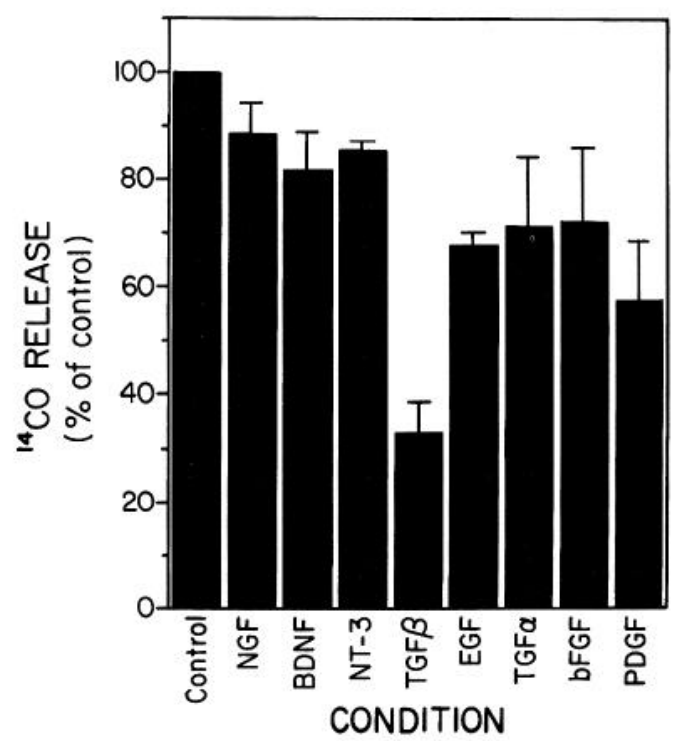

Figure 6. Effects of peptide growth factors on $\mathrm{CO}$ production in primary cultures of olfactory receptor neurons. Approximately $6 \mathrm{hr}$ after cell plating, the feeding medium was replaced with fresh medium containing $10 \mathrm{ng} / \mathrm{ml}$ of the indicated peptide growth factors. On day 3 , ${ }^{14} \mathrm{CO}$ production was measured to determine the effect of each peptide growth factor. Data are presented as the mean of two to four independent experimental determinations. Of all factors tested, TGF- $\beta 2$ demonstrates the largest effect on ${ }^{14} \mathrm{CO}$ production. is known to be an activator of soluble guanylyl cyclase like NO, and $\mathrm{HO}-2$ has been localized to discrete brain regions where it colocalizes with soluble guanylyl cyclase, direct demonstration of $\mathrm{CO}$ production by neurons has been lacking. Using ${ }^{14} \mathrm{C}$-glycine to metabolically label heme, it is now directly demonstrated that olfactory receptor neurons in culture are capable of modulating $\mathrm{CO}$ production by $\mathrm{HO}$ and that this rate of production is high. Brain tissues have long been known to have HO enzymatic activity, which could be measured in the presence of exogenous substrates when assays were performed in vitro. However, this is the first direct demonstration of $\mathrm{CO}$ produced physiologically from heme synthesized endogenously by neurons. Although basal levels are quite high, $\mathrm{CO}$ production changes dramatically during neuronal maturation in culture and the peak of $\mathrm{CO}$ production corresponds to the immature stage of olfactory receptor neuron development in culture. The total amount of $\mathrm{CO}$ production from glycine in olfactory receptor neurons was calculated to be approximately $100 \mathrm{pmol} / \mathrm{mg}$ protein. This may underestimate the actual $\mathrm{CO}$ production since only unbound $\mathrm{CO}$ was measured. In fact, olfactory receptor neurons in culture demonstrate considerably higher $\mathrm{HO}$ activity, as measured by the production of $\mathrm{CO}$, when compared with primary hepatocyte or cerebellar granule cell cultures (Ingi et al., unpublished data).

Initial interest in $\mathrm{CO}$ as a potential physiological messenger arose from a number of experiments which demonstrated that exogenous $\mathrm{CO}$ had biological effects similar to that of NO (Brüne and Ullrich, 1987; Marks et al., 1991). CO is known to inhibit platelet aggregation (Brüne and Ullrich, 1987) and it can produce relaxation in rabbit arterial preparations (Furchgott and Jothianandan, 1991). These activities were thought to be mediated by an activation of guanylyl cyclase by $\mathrm{CO}$. $\mathrm{CO}$ has subsequently been shown to cause increases in cGMP levels in cultured rat aortic smooth muscle cells (Ramos et al., 1989). Although several sources exist for the endogenous production of CO (Schmidt, 1992), the principal physiological pathway is by the action of $\mathrm{HO}$ which catalyzes the conversion of heme to biliverdin, releasing CO in the process (Lincoln et al., 1989). Of the two isoforms of $\mathrm{HO}$ thus far identified, HO-1 is inducible 
by heme and other agents such as transition and heavy metals; it is expressed at high levels in spleen and liver where its principal function is thought to be heme catabolism. The second isoform, $\mathrm{HO}-2$, is present in several peripheral tissues and in the brain, where it has been demonstrated to have discrete neuronal localization by in situ hybridization and immunohistochemistry. Thus, a large number of observations concerning endogenous production of $\mathrm{CO}$ and its potential messenger role have focused on HO and have made use of HO inhibitors to study this process in various cell preparations (Stevens and Wang, 1993; Zhuo et al., 1993; Prabhakar et al., 1995).

To support a physiological role for $\mathrm{CO}$ produced by $\mathrm{HO}$ as a mediator of guanylyl cyclase activation, in situ hybridization for HO-2 and soluble guanylyl cyclase demonstrated that these two enzymes colocalize in large degree to discrete neuronal populations in general, overlapping more consistently than the localization of neuronal NOS and guanylyl cyclase (Verma et al., 1993). The highest concentrations of HO-2 occur in olfactory epithelium and in olfactory bulb. The finding of high levels of HO- 2 mRNA by in situ hybridization prompted these studies to investigate the possibility that $\mathrm{CO}$ is a mediator of cGMP levels in these cells by using primary cultures of olfactory receptor neurons as an in vitro model. However, the direct measurement of $\mathrm{CO}$ production by $\mathrm{HO}$ in correlation to cGMP levels could not be made. More recent studies have supported the hypothesis that NO and CO production may be involved in LTP in the hippocampus (Schuman and Madison, 1991a; Stevens and Wang, 1993; Zhuo et al., 1993). Although ZnPP-9 or ZnBG block the induction of LTP in the hippocampus if applied before tetanus (Stevens and Wang, 1993; Zhuo et al., 1993) and reverse established LTP when administered after tetanic stimulation (Stevens and Wang, 1993), the role of CO in LTP has been controversial. Some reports suggest that ZnPP-9 could be reducing LTP via NOS inhibition, because ZnPP-9 can inhibit NOS activity in hippocampal tissues (Meffert et al, 1994).

For this reason, we used the olfactory receptor neuron as a model system as it has abundant HO-2 expression but lacks neuronal NOS, making it an excellent model for the studying the role of CO. The lack of neuronal NOS has been demonstrated immunohistochemically, by Northern blot analysis, by protein immunoblot, by PCR and by catalytic assay using ${ }^{3} \mathrm{H}$-arginine to ${ }^{3} \mathrm{H}$-citrulline conversion (Verma et al., 1993; Roskams et al., 1994). Furthermore, our data herein presented indicate that 0.1 mM NAME, a potent inhibitor of NOS, fails to significantly alter cGMP levels in our olfactory receptor neuron cultures.

By immunohistochemistry, we now show at a higher resolution that $\mathrm{HO}-2$ and soluble guanylyl cyclase immunoreactivities colocalize to olfactory receptor neurons, being expressed in cilia, cell bodies, and axon bundles. Similar staining patterns are obtained with two different antibodies raised against either HO-2 or soluble guanylyl cyclase. Of interest, although soluble guanylyl cyclase immunoreactivity is seen from most immature to mature olfactory receptor neurons in the epithelium, HO-2 immunoreactivity is absent from the most immature basally located olfactory receptor neurons. This suggests that HO-2 might play a role at later stages of maturation or in maturely functioning neurons competent for odorant signal transduction, whereas soluble guanylyl cyclase may have broader functions and may be involved in signaling processes at even earlier stages of neuronal development.

To directly demonstrate that CO production mediates cGMP levels in these cells, we have now developed a method by which heme can be metabolically labeled and the production of $\mathrm{CO}$ directly determined. CO production is especially high in these cells, in a biological range where it could act as an activator of soluble guanylyl cyclase (1-5 $\mu \mathrm{M}$ or $10-50 \mathrm{pmol} / \mathrm{mg}$ protein). In the third days of culture, at which time cells are reextending processes and maturing, there is a peak of ${ }^{14} \mathrm{CO}$ production which essentially parallels cGMP levels. These curves may not completely overlap as ${ }^{14} \mathrm{CO}$ production is measured over several hours in culture, whereas cGMP levels can be measured only at discrete time points. These cxpcrimental restraints may therefore result in some diversions in the peaks of these two activities. Taking into account endogenous glycine pools, the total level of $\mathrm{CO}$ produced from glycine is $100 \mathrm{pmol} / \mathrm{mg}$ protein. By using several inhibitors of $\mathrm{HO}$, we demonstrate that $\mathrm{CO}$ production is sensitive to these inhibitors and that cGMP levels reduce with the same $\mathrm{IC}_{50}$ as for the reduction of $\mathrm{CO}$ production. A concern in the literature is that there is some evidence that ZnPP-9 can directly inhibit guanylyl cyclase activity in vitro (Ignarro et al., 1984). To determine whether ZnPP-9 was acting at the level of guanylyl cyclase in cultured olfactory receptor neurons, we conducted extensive condition media transfer experiments with ZnPP-9 and ZnBG. Our data indicate that these inhibitors act at the level of HO but not at the level of guanylyl cyclase.

Nothing about neuronal regulation of $\mathrm{HO}$ activity has been known, but we now directly demonstrate that $\mathrm{CO}$ production changes dramatically during neuronal maturation. The increase in $\mathrm{CO}$ production and cGMP levels during the early phases of neurite outgrowth in culture, and the down-regulation of $\mathrm{CO}$ by TGF- $\beta 2$, suggest that the signaling pathway may function in phases of olfactory receptor neuron development. Recent studies show that ${ }^{3} \mathrm{H}$-thymidine labeling of olfactory neurons in culture peaks at $36 \mathrm{hr}$ after cell plating, indicating that postmitotic neurons must develop at the end of day 2 (Calof, Chikaraishi, 1989). This time corresponds to the maximum time of ${ }^{14} \mathrm{CO}$ release and endogenous cGMP levels in culture. The control of $\mathrm{CO}$ by TGF$\beta 2$ suggests that $C O$ release is likely to occur in the steps of neuronal precursor proliferation or precursor differentiation into postmitotic neurons. During the time of neurogenesis when TGF- $\beta 2$ has its effect, mediation of this effect may require $\mathrm{CO}$ levels to fall so that other cellular differentiation responses can be activated. TGF- $\beta 2$ is known to be an olfactory neurogenic or survival factor. It can initiate terminal differentiation in olfactory receptor neurons by presumably activating TGF- $\beta$ receptors on the surface of these cells. TGF- $\beta 2$ lowered cGMP levels to about $70 \%$ of control at day 3 when TGF- $\beta 2$ clearly suppressed the peak of CO production, which supports the correlation of $\mathrm{CO}$ and $\mathrm{cGMP}$ levels. The exact role of $\mathrm{CO}$ in TGF- $\beta$ signal transduction remains to be determined. Further elucidation of this mechanism may help further our understanding the reg ulation and role of $\mathrm{CO}$ in neuronal physiology and maturation.

\section{References}

Bredt DS, Snyder SH (1994) Transient nitric oxide synthase neurons in embryonic cerebral cortical plate, sensory ganglia, and olfactory neurons. Neuron, in press.

Brüne B, Ullrich V (1987) Inhibition of platelet aggregation by carbon monoxide is mediated by activation of guanylate cyclas. Mol Pharmacol 32:497-504.

Calof AL, Chikaraishi DM (1989) Analysis of neurogenesis in a mammalian neuroepithelium: proliferation and differentiation of an olfactory neuron precursor in vitro. Neuron 3:115-127.

Cruse I, Maines MD (1988) Evidence suggesting that the two forms of heme oxygenase are products of different genes. J Biol Chem 263: $3348-3353$. 
DeIlamer MK, Guevara JL, IIannon K, Olwin BB, Calof AL (1994) Genesis of olfactory receptor neurons in vitro. Regulation of progenitor cell divisions by fibroblast growth factors. Neuron 13:1083-1097.

Ernfors P, Lönnerberg P, Ayer-LeLievre C, Persson H (1990) Developmental and regional expression of basic fibroblast growth factor mRNA in the rat central nervous system. Neuroscience 27:10-15.

Ewing JF, Maines MD (1992) In situ hybridization and immunohistochemical localization of heme oxygenase- 2 mRNA and protein in normal rat brain: differential distribution of isozyme 1 and 2 cell. Mol Cell Neurosci 3:559-570.

Freeman ME, Lane JD, Smith JE (1983) Turnover rates of amino acid neurotransmitters in regions of rat cerebellum. J Neurochem 40: 1441-1447.

Furchgott RF, Jothianandan D (1991) Endothelium-dependent and-independent vasodilation involving cyclic GMP: relaxation induced by nitric oxide, carbon monoxide and light. Blood Vessels 28:52-61.

Glaum SR, Miller RJ (1993) Zinc protoporphyrin-IX blocks the effects of metabotropic glutamate receptor activation in the rat nucleus tractus solitarii. Mol Pharmacol 43:965-969.

Gonzalez C, Almaraz L, Obeso A, Rigual R (1992) Oxygen and acid chemoreception in the carotid body chemoreceptors. Trends Neurosci 15:146-153.

Gräser T, Vedernikov YP, Li DS (1990) Study on the mechanism of carbon monoxide induced endothelium-independent relaxation in porcine coronary artery and vein. Biomed Biochim Acta 49:293-296.

Graziadei PPC, Graziadei M (1978) The olfactory system: a model for the study of neurogenesis and axon regeneration in mammals. In: Neuronal plasticity (CWC, ed), pp 131-153. New York: Raven.

Guthrie KM, Gall CM (1991) Differential expression of mRNAs for the NGF family of neurotrophic factors in the adult rat central olfactory system. J Comp Neurol 313:95-102.

Hall PV, Smith JE, Lane J, Mote TBA, Campbell R (1979) Glycine and experimental spinal spasticity. Neuro 29:262-267.

Ignarro LJ, Ballot B, Wood KS (1984) Regulation of soluble guanylyl cyclase activity by porphyrins and metalloporphyrins. J Biol Chem 259:6201-6207.

Landaw SA, Winchell HS (1966) Endogenous production of carbon14 labeled carbon monoxide: an in vivo technique for the study of heme catabolism. J Nucl Med 7:696-707.

Lincoln BC, Aw TY, Bonkovsky HL (1989) Heme catabolism in cultured hepatocytes: evidence that heme oxygenase is the predominant pathway and that a proportion of synthesized heme is converted rapidly to biliverdin. Biochim Biophys Acta 992:49-58.

Mahanthappa NK, Schwarting GA (1993) Peptide growth factor control of olfactory neurogenesis and neuron survival in vitro: roles of EGF and TGF-Bs. Neuron 10:293-305.

Maines MD (1981) Zinc . . protoporphyrin is a selective inhibitor of hente oxygenase activity in the neonatal rat. Biochin Biophys Acta 673:339-350.

Maines MD (1988) Heme oxygenase: function, multiplicity, regulatory mechanisms, and clinical applications. FASEB J 2:2557-2568.

Maines MD, Mark JA, Ewing JF (1993) Heme oxygenase, a likely regulator of cGMP production in the brain: induction in vivo of $\mathrm{HO}-1$ compensates for depression in NO synthase activity. Mol Cell Neurosci 4:398-405.

Margolis FL, Roberts N, Ferriero D, Feldman J (1974) Denervation in the primary olfactory pathway of micc: biochemical and morphological effects. Brain Res 81:469 -483 .

Marks GS, Brien JF, Nakatsu K, McLaughlin BE (1991) Does carbon monoxide have a physiological function? Trends Pharmacol Sci 12: 185-188.

Meffert MK, Haley JE, Schuman EM, Schulman H, Madison DV (1994) Inhibition of hippocampal heme oxygenase, nitric oxide synthase, and long-term potentiation by metalloporphyrins. Neuron 13: $1225-1233$.

Moncada S, Palmer RMJ, Higgs EA (1991) Nitric oxide: physiology, pathophysiology and pharmacology. Pharmacol Rev 43:109-142.

Nudel U, Zakut R, Shani M, Neuman S, Levy Z, Yaffe D (1983) The nucleotide sequence of the rat cytoplasm $\beta$-actin gene. Nucleic Acids Res 11:1759-1771.

Pixley SK (1992) CNS glial cells support in vitro survival, division, and differentiation of dissociated olfactory neuronal progenitor cells. Neuron 8:1191-1204.

Prabhakar NR, Dinerman JL, Agani FH, Snyder SH (1995) Carbon monoxide: a role in carotid body chemoreception. Proc Natl Acad Sci USA 15:48-46, in press.

Ramos KS, Lin H, McGrath JJ (1989) Modulation of cyclic guanosine monophosphate levels in cultured aortic smooth muscle cells by carbon monoxide. Biochem Pharmacol 38:1368-1370.

Ronnett GV, Hester LD, Snyder SH (1991) Primary culture of neonatal rat olfactory neurons. J Neurosci 11:1243-1255.

Roskams AJ, Bredt DS, Dawson TM, Ronnett GV (1994) Nitric oxide mediates the formation of synaptic connections in developing and regenerating olfactory receptor neurons. Neuron 13:289-299.

Rotenberg MO, Maines MD (1990) Isolation, characterization and expression in Escherichia coli of a cDNA encoding rat heme oxygenase-2. J Biol Chem 265:7501-7506.

Sasahara A, Kott IN, Sasahara M, Raines FW, Ross R, Westrum LE (1992) Platelet-derived growth factor B-chain-like immunoreactivity in the developing and adult rat brain. Dev Brain Res 68:41-53.

Schmidt HHHW (1992) NO.CO and $\cdot \mathrm{OH}$ endogenous soluble guanylyl cyclase-activating factors. FEBS Lett 307:102-107.

Schuman EM, Madison DV (1991a) The intercellular messenger nitric oxide is required for long-term potentiation. Science 254:1503-1506.

Schuman ER, Madison DV (1991b) A requirement for the intercellular messenger nitric oxide in long-term potentiation. Science 254:15031506.

Stevens CF, Wang Y (1993) Reversal of long-term potentiation by inhibitors of haem oxygenase. Nature 364:147-148.

Stone JR, Marletta MA (1994) Soluble guanylyl cyclase from bovine lung: activation with nitric oxide and carbon monoxide and spectral characterization of the ferrous and ferric states. Biochemistry 33: $5636-5640$.

Sun Y, Rotenberg MO, Maines MD (1990) Developmental expression of heme oxygenase isozymes in rat brain. Two HO-2 mRNAs are detected. J Biol Chem 265:8212-8217.

Verma A, Hirsch DJ, Glatt CE, Ronnett GV, Snyder SH (1993) Carbon monoxide: a putative neural messenger. Science 259:381-384.

Vreman HJ, Lee OH, Stevenson DK (1991) In vitro and in vivo characteristics of a heme oxygenase inhibitor: $\mathrm{ZnBG}$. Am J Med Sci 302: 335-341.

Zhuo M, Small SA, Kandel ER, Hawkins RD (1993) Nitric oxide and carbon monoxide produce activity-dependent long-term synaptic enhancement in hippocampus. Science 260:1916-1950. 